\title{
EVALUATION OF THE LOCAL GEODETIC NETWORK IN JURMALA CITY
}

\author{
Celms Armands, Reke Ilona, Brinkmanis-Brimanis Miks, Vivita Pukite \\ Latvia University of Life Sciences and Technologies
}

\begin{abstract}
In order to evaluate the accuracy of the local geodetic network of Jurmala City, in research, comparison of fortyseven selected polygonometry network point coordinates with the obtained data was made by performing measurements by real time cinematic (RTK) method in LatPos base station system. Points were chosen so in order to cover evenly the entire territory of the city. At present, gradual renewal and improvement of the local geodetic network takes place in Jurmala. The linear discrepancy of coordinates obtained in measurements varies from $0.016 \mathrm{~m}$ to $0.259 \mathrm{~m}$, mean linear discrepancy in the measured points is fixed $0.110 \mathrm{~m}$. Discrepancy of plane coordinates in different regions of Jurmala is not even. It is rather even within approximate boundaries of the determined regions, this is indicated by different directions of offset vectors, which in eastern part of the city are pointed mainly in NW direction, in central part directions are pointed in $\mathrm{W}$ direction, but in the western part of the city pointed in NE direction. Concerning heights, only for 3 of measured points discrepancy exceeds $0.05 \mathrm{~m}$ error and there are no connection concerning some specific region. 15\% of the measured points of the local geodetic network are with appropriate accuracy of plane coordinates. The linear discrepancy of plane coordinates for points of the local geodetic network, which are measured by RTK method and compared with data from the improved network is $0.024(\mathrm{~m})$, which indicates the high accuracy of RTK method in measurement data. In Jurmala City, obtaining of data by GNNS data receivers is encumbered by large density of trees. Therefore the local geodetic network in city has very important role in order to ensure performance of geodetic measurements of high quality in the territory of the city. Aim of the research is to evaluate the accuracy of the local geodetic network of Jurmala City. The following tasks have been set for achieving the aim: research of the given problem, visit of the local geodetic network points, performing control measurements, data processing and analysis.
\end{abstract}

Key words: RTK, LatPos, LKS-92, GNNS, Local Geodetic Network

\section{Introduction}

In the last decade, geodetic infrastructure in world-wide scale has developed very rapidly. The growth of the industry was furthered mainly by the demand in diverse sectors of economics, both in civil sector and in national defense sector. Development of global satellite navigation system (GNSS) nowadays has given a possibility to establish geodetic networks with high accuracy providing possibility of geodetic measurements with millimeter accuracy.

In Latvia, set of geodetic points forms basic networks of two types - national geodetic network and local geodetic network. Both geodetic networks are functioning in Latvian coordinate system LKS-92 (Celms et al, 2018).

The national geodetic network provides the united geodetic reference system in the entire territory of Latvia (Balodis et al, 2016). It includes GPS, Leveling, Gravimetric, Geomagnetic and LatPos base station network. These networks are maintained by Latvian Geospatial Information Agency (LGIA). Its main tasks are implementation of state policy in area of geodesy, cartography and geospatial information. The local geodetic network is necessary in order to provide united coordinate system for surveying works in specific administrative territory. In Latvia, geodetic reference points are necessary for cadastral surveying, provision of operation of real estate state cadastre information system, obtaining of topographic data of high minuteness and performance of other geodetic works: designing, construction and operation of objects. The local geodetic network is maintained by the corresponding local municipality according to Regulations of the Minister Cabinet of 24 July, 2012 No. 497,,Regulations of the local geodetic network" (Vieteja geodeziska..., 2012).

Accuracy of the local networks corresponds to the time, when they were established As the technologies and methods in geodesy develop, possibility arises to draw conclusions on condition and accuracy of the network according of contemporary requirements. Point 4 of Regulations of the Minister Cabinet No.497 prescribes that the local geodetic network is created by linking to the national geodetic network with 3-6 cm accuracy. Not always this prescribed accuracy against the national geodetic network can be observed. As a result problems arise to align measurement data obtained from the same network at different time. 
In order to evaluate the accuracy of the local geodetic network of Jurmala City, purpose of the research was to determine offsets of plane coordinates of the local geodetic network in relation to national geodetic network by GNSS receiver in LatPos base station system.

For the achievement of the purpose following tasks were set: inspect and survey points of the local geodetic network in the territory of Jurmala by GNSS RTK (real time cinematic method) in LATPOS station network system; carry out processing of measurement data and analysis of the obtained results; create cartographic material by depicting the obtained offsets.

Research is suitable for usage of information for municipality of Jurmala concerning compliance of the local network with requirements

\section{Methodology of research and materials}

For obtaining of data, GNNS receiver in the method RTK in 180 seconds sessions was used. In data processing, software Microsoft Office and software Bentley Microstation was used (Dobelis, Zvirgzds, 2016; Dobelis, Zvirgzds, Kalinka, 2016).

In municipality of Jurmala City according to Point 64 of Regulations of the Minister Cabinet No.497 the first time inspection and evaluation is carried out. According to local network inspection report, 740 points were inspected in the territory of Jurmala City. Act on destroying of points of the local network is compiled for 204 points (See Fig. 1)

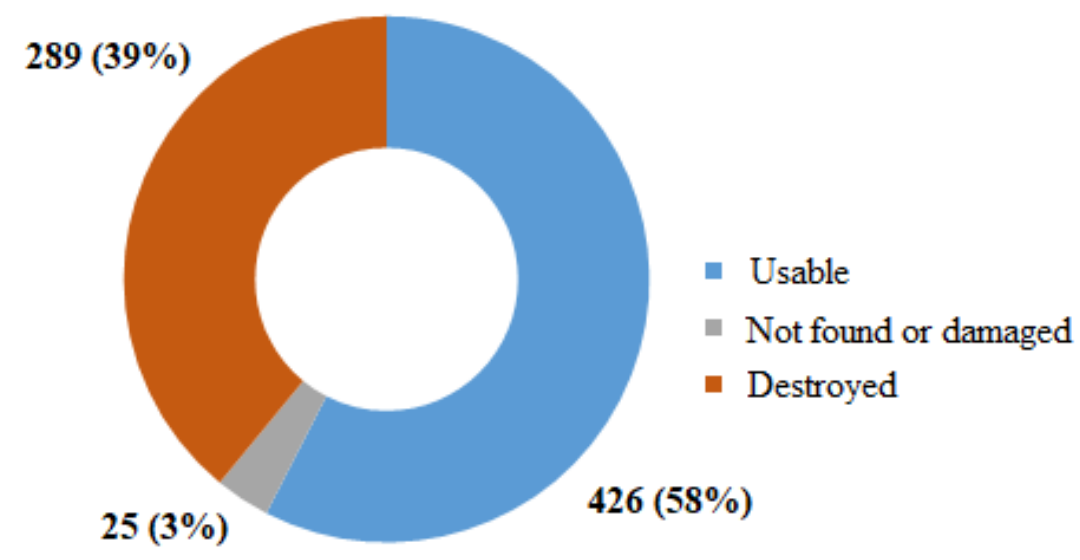

Fig. 1 Distribution of points of the local network of Jurmala City (Compiled by the Author).

After the inspection and evaluation it was stated that the local network does not comply with requirements mentioned in the point 4 of the Regulations of the Minister Cabinet No. 479: "The local network is created by linking it to the national geodetic network (hereinafter - national network) with 3-6 cm accuracy: heights of geodetic points are determined with standard deviation up to $1 \mathrm{~cm}$, coordinates - up to 2 cm" Report: (Atskaite: Vieteja geodeziska..., 2012).

For Jurmala City, descriptions of improvement of points of the local network are elaborated and opinions of Latvian Geospatial Information Agency on above-mentioned descriptions are received.

Jurmala City is covered by pine forests and individually growing pines, as well as by dense build-up areas, which encumbered possibility to carry out surveying and determination of coordinates of geodetic points by GNSS methods.

Taking into account the above and based on point 14 of the first part of the Article 15, point 23 of the first part of article 21 of the law "On municipalities" and point 17 of the Regulations of the Minister Cabinet of 24 July, 2012 No. 497 „Regulations of the local geodetic network”, Council of Jurmala City decided to carry out gradual improvement of the local network of Jurmala City and renewal of geodetic data, as well as to improve the local network of Jurmala City according to descriptions of improvement.

The prioritary territories of improvement of the local network were determined:

- Bulluciems, Lielupe, Bulduri, part of Dzintari - stage 1, 2;

- part of Dzintari, Majori, part of Dubulti - stage 3;

- part of Dubulti, Jaundubulti, Pumpuri, Druvciems, part of Melluži - stage 4;

- part of Melluži, Asari, part of Vaivari, Valteri - stage 5;

- part of Vaivari, Krastciems - stage 6;

- Sloka, Kauguri, Kaugurciems, part of Jaunķemeri - stage 7; 
- Ķemeri - stage 8.

It was decided to carry out improvement of the local network situated in area of Jurmala City bypass road A10, Priedaine, Vārnukrogs, Bullıciems (area of port), planned Jaundubulti bridge and P128 bypass road in the framework of construction works envisaged in the future. Decision was taken to do not improve the local network in forests of Priedaine, Druvciems, Valteri, Krastciems, Kemeri, Jaunķemeri and Kūdra, where economic activity is absent. Until now, the improvement of the local geodetic network is carried out only in eastern part of the city in Bulluciems, Lielupe, Bulduri and in western part of the City along Talsi Highway up to Kolka Street.

\section{Discussion and results}

Evaluation of accuracy of plane coordinates of the local geodetic network in Jurmala City. In order to carry out evaluation of plane coordinates of the local geodetic network of Jurmala in relation to the National geodetic network that is in system LKS-92 TM, before the performance of measurements cartographic material with locations of polygonometry points was analyzed. Map material in question was in DGN format. By use of Bentley Microstation software and alignment with ADTI city mapsheets, it is possible to make first conclusions on location of the point and surroundings - buildings, trees, roads and other objects of urban environment. When points, plane coordinates of which are to evaluate, were chosen, the main requirement was that they should cover evenly the entire territory of Jurmala City -in each region of city at least 2-3 polygonometry points.

For the selected points, sketches with distances to the nearest objects were prepared. Inspection of the selected points of the local geodetic network was started from the easternmost part of city (region Vārnukrogs) and went to the western part (region Ķemeri). As the points were inspected a large part of the selected points was declared inappropriate, because it is not possible to determine coordinates by GNSS data receiver in appropriate accuracy. The main reason is cover of trees that does not allow to receive signal broadcasted by satellites. In the inspection of poligonometry points, author's knowledge about a part of the selected points and their accurate location acquired, when he worked in area of surveying in Jurmala city, was helpful. Fact that the local geodetic network of Jurmala is used practically in everyday life for the purposes of performance of geodetic works. Most of points of polygonometry network is practically used, and as a result of activities of surveyors there are unclosed holes around points or inserted signal pole.

Out of the selected points,

47 points of the local geodetic network of Jurmala City complied with measurements. Still such obstacles as the dense tree cover or points of polygonometry network destroyed in some parts of the city limited the possibility to carry out measurements evenly, covering the entire territory of the city. For the selected 47 points of the local geodetic network, determination of X,Y coordinates by GNSS data receiver in RTK method in 180 seconds sessions, in LatPos base system was carried out.

For the determination of coordinates GNSS data receiver CHC x91 was used. The receiver has 220

channels that receive following GNSS satellite signals:

- NAVSTAR : (L1C/A,L2C, L2E, L5)

- GLONASS: (L1C/A, L1P, L2C/A, L2P)

- SBAS: (WAAS, EGNOS, MSAS) 2010).

- GALILEO: (GIOVEA and GIOVEB) (CHC to supply..., 2013; Getting started guide...,

GNSS receiver gives possibility to see DOP values, as well as measuring in RTK method with following accuracy parameters:

- Horizontal accuracy up to $\pm 10 \mathrm{~mm}$

- Vertical accuracy up to $\pm 20 \mathrm{~mm}$

- Initialization time $10 \mathrm{~s}$

- Initialization reliability $>99.9 \%$ (Atskaite: Vieteja geodeziska..., 2012).

Analysis of the RTK measurements of the local geodetic network. Control measurements were performed in March 2018, in 47 polygonometry points of the local geodetic network (See Fig. 2) during two weeks. Plane coordinates are determined in RTK method, in 180 seconds session, by placing GNSS data receiver over polygonometry points, and by use of carbon fiber spoke with spherical level. All measurements are carried out in FIXED position that guarantees data flow from at least 5 GNSS satellites. 


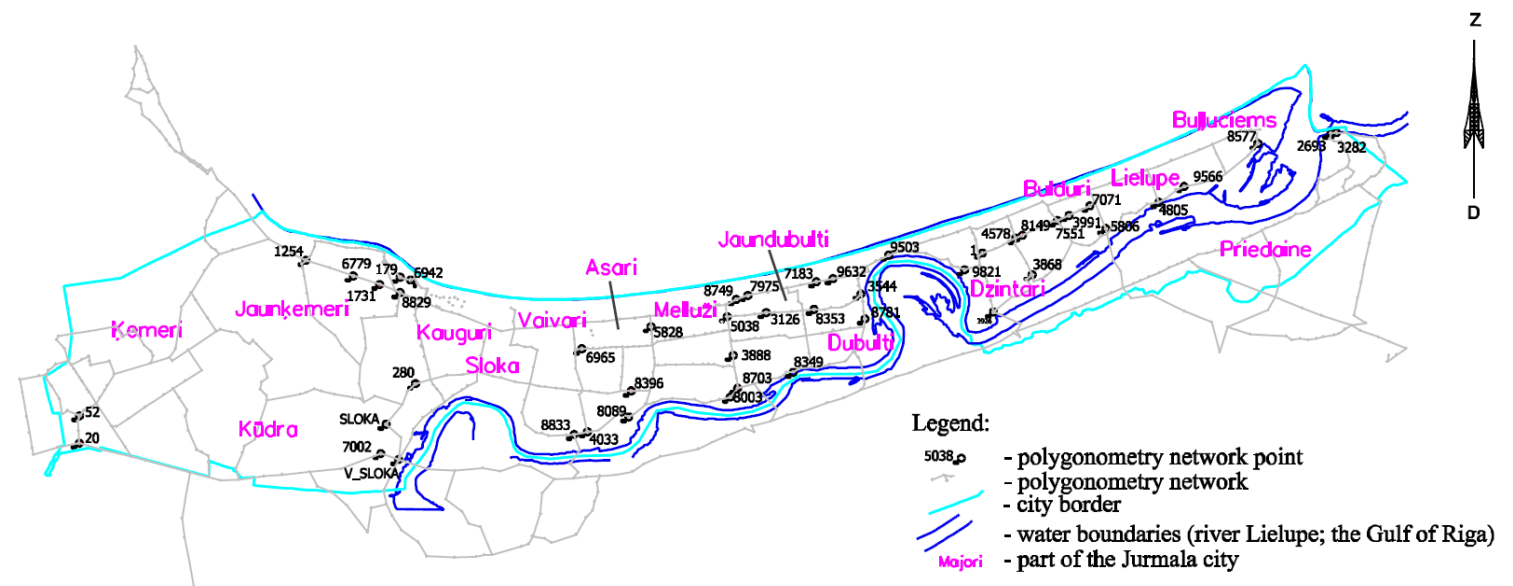

Fig. 2 Scheme of polygonometry network of Jurmala City (Compiled by the Author).

In order to compare plane coordinates obtained in RTK measurements with coordinates from catalogue of polygonometry points more demonstratively, calculations of linear discrepancy are made by use of Pithagorean theorem. Calculations are carried out according to formula:

f-linear discrepancy

$$
f=\sqrt{f x^{2}+f y^{2}}
$$

$\mathrm{f}_{\mathrm{x}}$-coordinate discrepancy along $\mathrm{x}$ axis

$f_{\mathrm{y}}$-coordinate discrepancy along y axis

Linear discrepancy of coordinates obtained in control measurements from coordinates from catalogue varies from $0.016 \mathrm{~m}$ up to $0.259 \mathrm{~m}$. Mean linear discrepancy in the measured points is fixed $0.110 \mathrm{~m}$. The largest discrepancies are stated in area of Lielupe, Bulduri, Dzintari and Majori, where it is 0.214 $\mathrm{m}$ in average. Polygonometry points in most areas of Jurmala City do not comply with requirements of point 4 of Regulations of Minister Cabinet No.497 "Regulations of the local geodetic network". The local network shall be linked to the national geodetic network with 3-6 cm accuracy (Vieteja geodeziska tikla..., 2012). Areas, where control measurements of points of the local geodetic network demonstrated appropriate accuracy are Melluži, Valteri, Druvciems, Krastciems and Ķemeri (See Fig. 3).
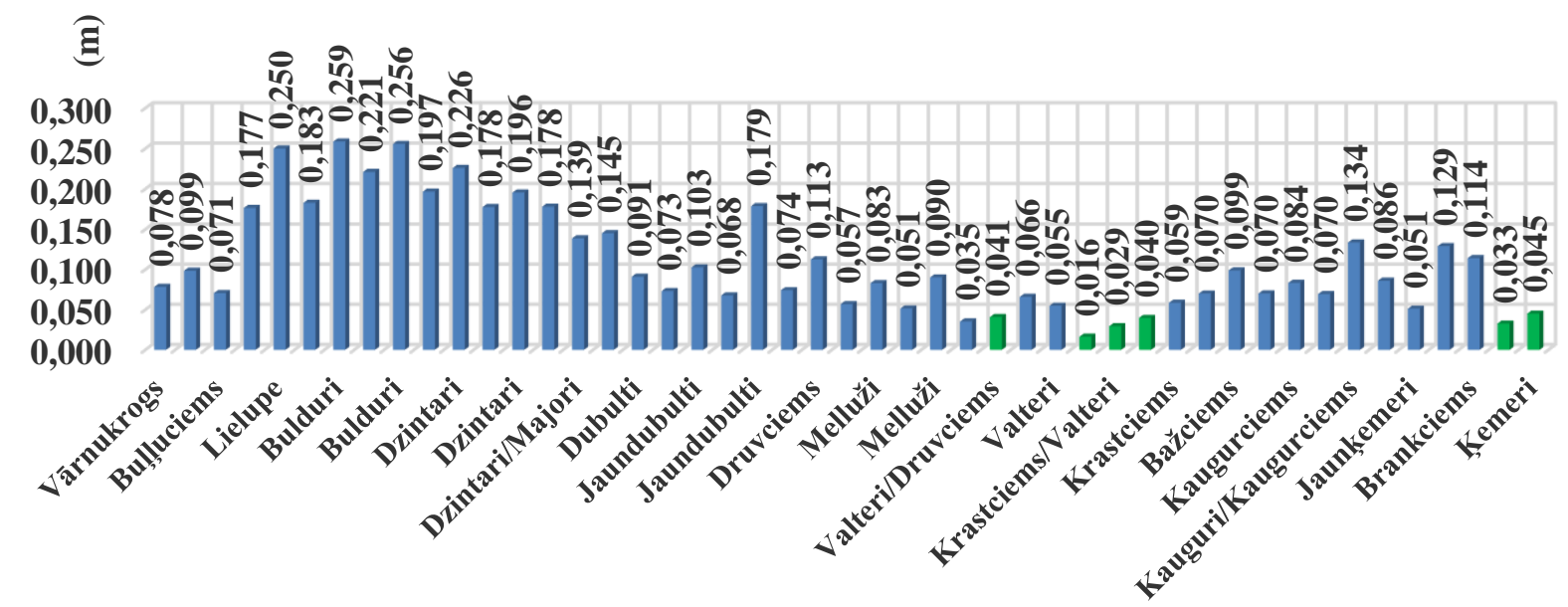

Fig. 3 Linear discrepancies of control measurements of RTK method in LatPos base station system in relation to the local geodetic network (Compiled by the Author).

If we compare heights of points of the local geodetic network of control measurements and heights available in catalogue, the situation is much more positive. If we assume that values are positive and do not exceed $0.05 \mathrm{~m}$ error, then only 3 out of 47 measured points are beyond this limit. No relationships can be observed concerning any specific area (See Fig.4). 


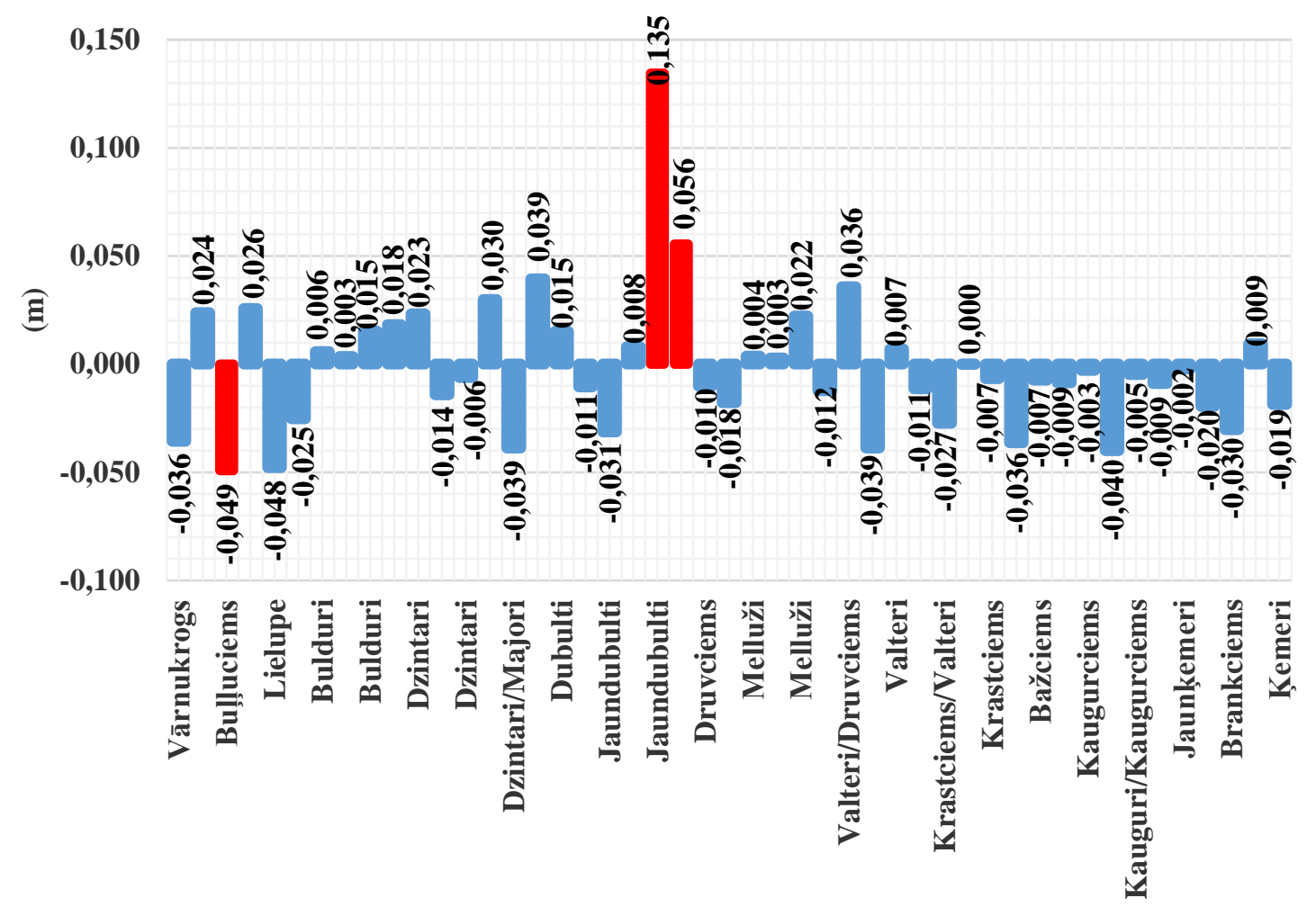

Fig. 4 Vertical discrepancies of control measurements of RTK method in LatPos base station system in relation to heights of the local geodetic network (Compiled by the Author).

In percentage terms, only for $15 \%$ points, in which control measurements were carried out, XY linear discrepancy complies with requirements of the point 4 of Regulations of Minister Cabinet No.497 "Regulations of the local geodetic network" concerning 3-6 linking to the national geodetic network. Linear discrepancy of the rest of points is greater than prescribed requirements (See Fig. 5)

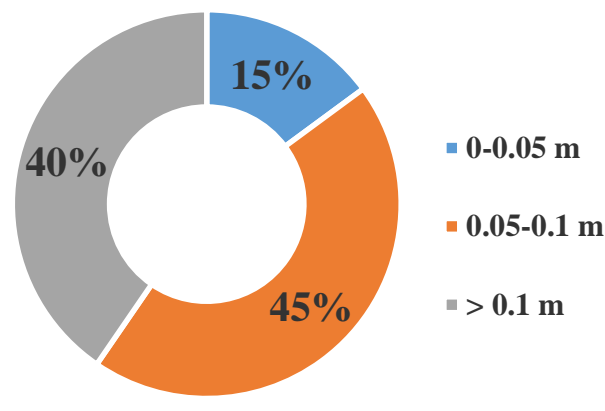

Fig. 5 Distribution of linear discrepancy of control measurements of RTK method in LatPos base station system in percentage terms in relation to the local geodetic network (Compiled by the Author).

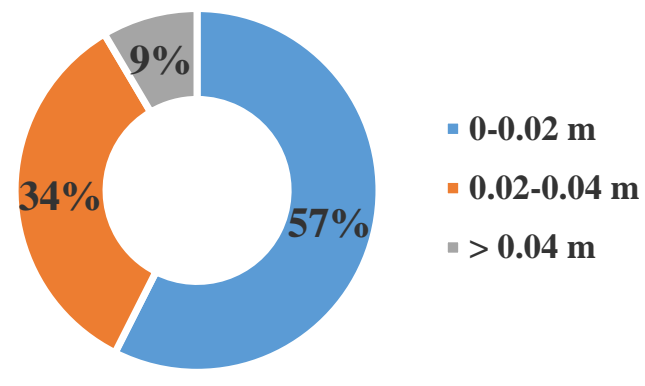

Fig. 6 Distribution of vertical discrepancy of control measurements of RTK method in LatPos base station system in percentage terms in relation to the local geodetic network (Compiled by the Author).

Vertical discrepancies in measurements demonstrated much better results, in $57 \%$ cases discrepancy did not exceed $0.02 \mathrm{~m}$ (See Fig. 6).

Coefficient of geometric placement of satellites PDOP, which has not exceeded 2.5 in any point, certifies about the quality of obtained data in control measurements by use of RTK method. Linear discrepancies of X, Y coordinates obtained in measurements and PDOP values, among which there are no interconnections, also certify about this (See Fig. 7). 


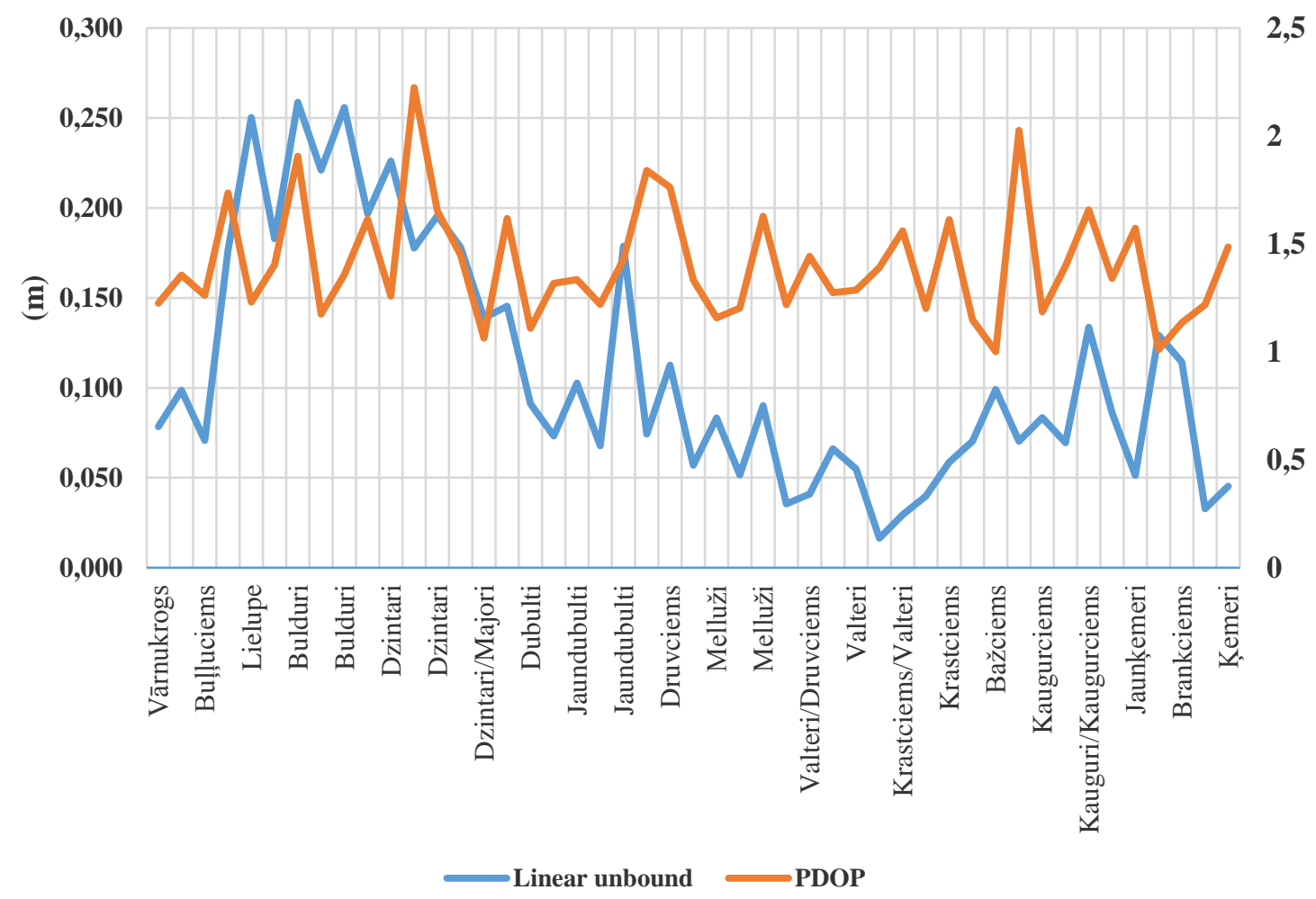

Fig. 7 Impact of geometric placement of satellites (PDOP) on control measurements in RTK method in LatPos base station system (Compiled by the Author).

In order to evaluate stability and accuracy of real time cinematic method control measurements, the obtained results were compared with data from the improved local geodetic network. 26 points were compared (See Fig. 8).

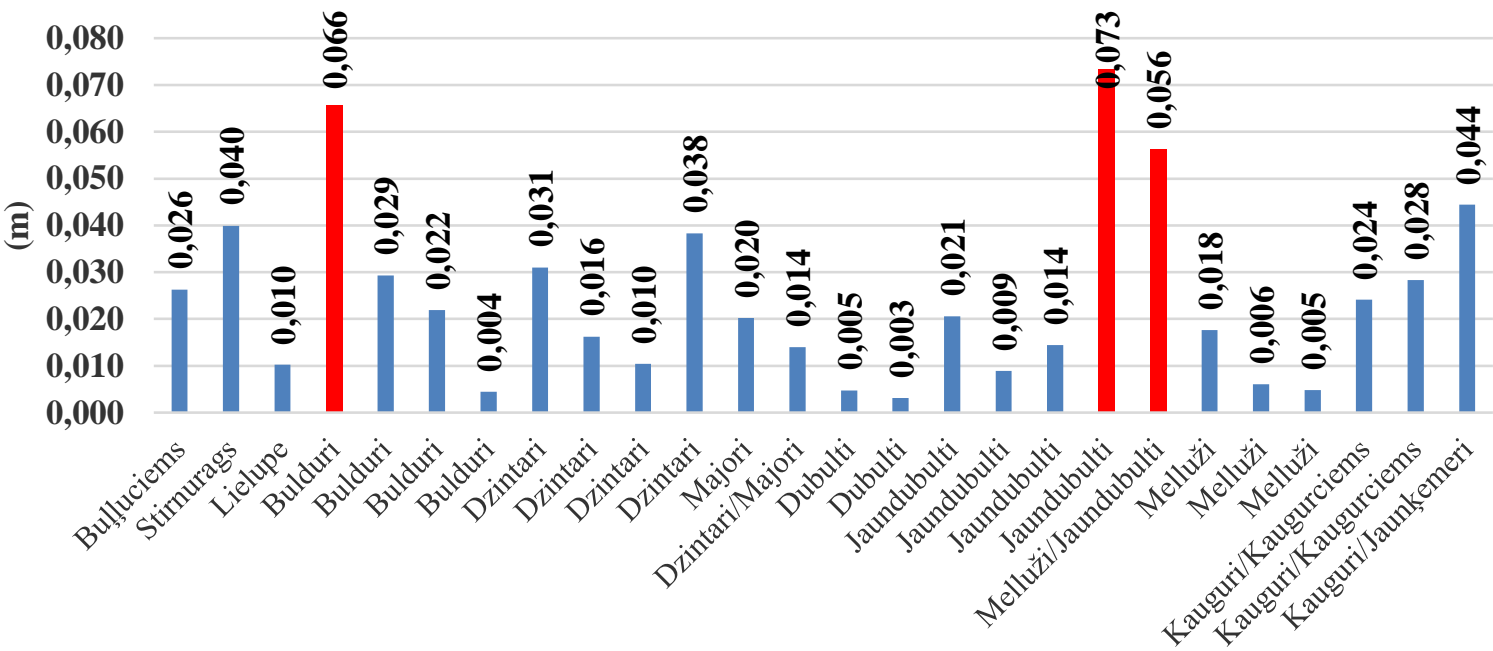

Fig. 8 Linear discrepancy of data of the improved local geodetic network from data obtained in RTK method (Compiled by the Author).

Average linear discrepancy was stated $0.024 \mathrm{~m}$. Only in 3 points of control measurements discrepancy that is greater than $0.04 \mathrm{~m}$ was fixed. One of points was situated in area of Bulduri, two in Melluži. As these three points were inspected one more time, conclusion was drawn that the possible obstacle for data accuracy was cover of trees (See Fig. 8).

As indices for $\mathrm{X}$ and $\mathrm{Y}$ axes are taken separately, discrepancy along $\mathrm{X}$ axis reaches 0.008 , along Y axis 0.007. (See Fig. 9) 


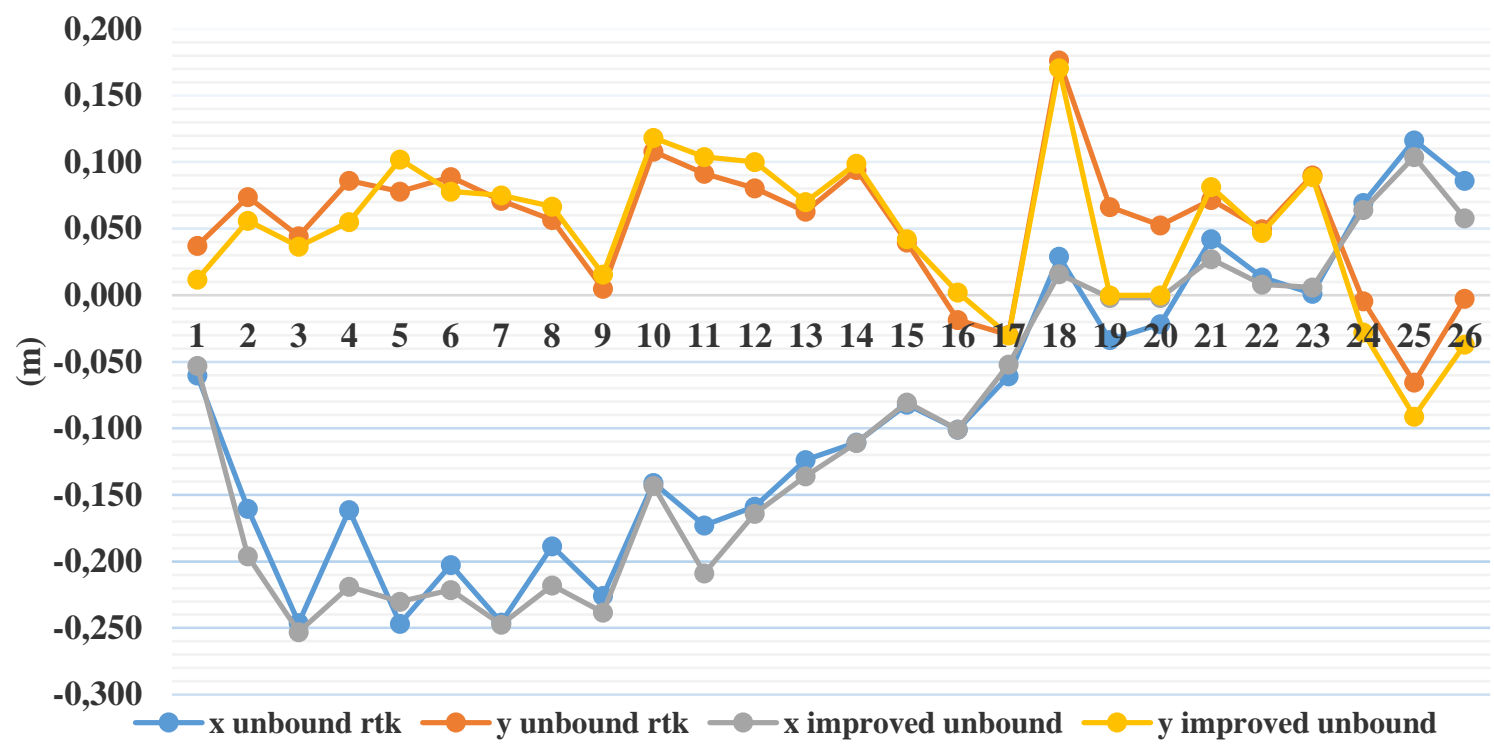

Fig. 9 Discrepancies along $X$ and $Y$ axes of data of control measurements obtained in RTK method from data of the improved local geodetic network (Compiled by the Author).

In order to clarify directions of plane coordinate discrepancies in areas of Jurmala City, cartographic material is created. In the eastern part of the city, vectors mainly are pointed in NW direction, in central part in $\mathrm{W}$ direction, but in the western part of the city are pointed mainly in NE direction, except Ķemeri, where vectors are pointed in NW direction. Direction of vectors of points of the eastern part of the city differs from results obtained in other regions, where the consequence is not so large (See Fig. 10).

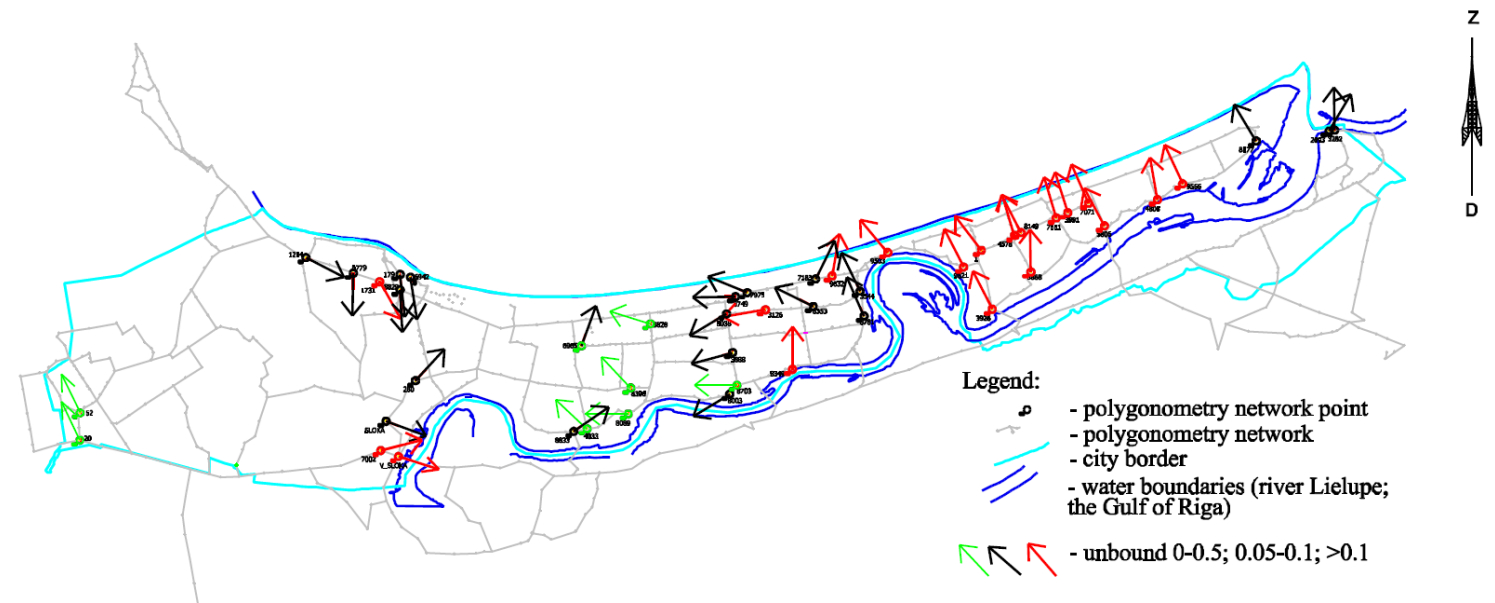

Fig. 10 Directions of vectors of offsets of plane coordinates of Jurmala City (Compiled by the Author).

Not equal directions of vectors and linear discrepancies in central and western parts of city certify about the fact that they have lost their accuracy in the result of natural factors and depreciation (See Fig. 10).

\section{Conclusions and proposals}

1. The average linear plane coordinate discrepancy of control measurements carried out by RTK method compared with coordinates of the local geodetic network from catalogue is $0.110(\mathrm{~m})$, but the average arithmetic discrepancy of heights is $0.022(\mathrm{~m})$.

2. Discrepancy of plane coordinates in diverse areas of Jurmala is not even. It is rather even within approximate boundaries of the determined areas. Also different directions of offset vectors that in the eastern part are pointed mainly in NW direction, in central part vectors are pointed in $\mathrm{W}$ direction, but in western part of the city are pointed in NE direction, except in Kemeri, where vector is pointed in NW direction.

3. Greatest plane coordinate offsets are fixed in the areas of the center of the city- in Lielupe, Bulduri, Dzintari and Majori. There average arithmetic discrepancy is $0.214 \mathrm{~m}$. Areas, where 
control measurements of the local geodetic network did not exceed $0.06 \mathrm{~m}$, which can be considered as appropriate accuracy, are Melluži, Valteri, Druvciems, Krastciems and Ķemeri.

4. $15 \%$ out of the measured points of the local geodetic network are with appropriate plane coordinate accuracy.

5. Linear discrepancy of plane coordinates for points of the local geodetic network measured by RTK method and compared with data from the improved network is 0.024 (m), which indicates the high accuracy of RTK method in measurement data.

6. In Jurmala City, obtaining of data by GNNS data receivers is encumbered by the dense tree cover. Therefore, the local geodetic network in city has a very important role, in order to provide performance of high quality geodetic measurements in its territory. The local geodetic network shall be maintained according to contemporary actual requirements for accuracy.

\section{References.}

1. Atskaite: Vietējā ǵeodēziskā tīkla pilnveidošanas apraksts (Report: description of local geodetic network optimization) (2012). Ventspils (in Latvian).

2. Balodis J., Morozova K., Silabriedis G., Kalinka M., Balodis K., Mitrofanovs I., Baltmane I., Jumare I. (2016) Changing the national height system and GEOID model in Latvia. Geodesy and Cartography Volume 42, Issue 1, p. 20-24.

3. Celms. A., Parsova V., Reke I., Akmentins J. (2018) Tendencies of development of local geodetic network in Riga city. Baltic Surveying, Volume 9. p. 8-15

4. CHC to supply 90 GNSS Receivers to Chinese National Mapping Bureau . (2013). Viewed 18 April, 2018, (https://www.geoconnexion.com/news/chc-to-supply-90-gnss-receivers-to-chinese-nationalmapping-bureau).

5. Dobelis D., Zvirgzds J. (2016) Network RTK performance analysis: a case study in Latvia. Geodesy and Cartography, Volume 42, Issue 3, p. 69-74.

6. Dobelis D., Zvirgzds J., Kaliinka M. (2017) High ionospheric activity effects on LatPos RTK network performance in Latvia. IOP Conference Series: Materials Science and Engineering. Viewed 18 June, 2018, (http://iopscience.iop.org/article/10.1088/1757-899X/251/1/012064/meta).

7. Getting started guide X91GNSS (2010). Viewed 19 April, 2018 (https://www.geoplan.hr/upute_za_\%20radX91.pdf)

8. Vietējā geodēziskā tīkla noteikumi (Regulation of local geodetic network) (2012). Viewed 25 January, 2018, (https://likumi.lv/doc.php?id=250460) (in Latvian).

\section{Information about author}

Armands Celms Dr.sc.ing, associate profesor of Department of Land Management and Geodesy at Latvia University of Life Sciences and Tehcnologies, Akademijas iela 19, Jelgava, LV-3001, armands.celms@1lu.lv Ilona Reke Mg.sc.ing, doctoral student of Department of Land Management and Geodesy at Latvia University of Life Sciences and Tehcnologies, Akademijas iela 19, Jelgava, LV-3001, ilona.reke@ gmail.com

Miks Brinkmanis-Brimanis Mg.sc.ing, land surveyor at GEO JURMALA Ltd., miksbrinkmanis@ inbox.lv Vivita Pukite, Dr.oec., associate profesor of Department of Land Management and Geodesy at Latvia University of Life Sciences and Tehcnologies, Akademijas iela 19, Jelgava, LV-3001, vivita.pukite@1lu.lv 